\title{
Effect of Carbon Dioxide and Temperature on Passive Film Parameters of Superduplex Stainless Steel
}

\author{
Emandro Vieira da Costa, Thiago José Mesquita ${ }^{\mathrm{b}}$, Ariane Ferreira, \\ Ricardo Pereira Nogueira ${ }^{\mathrm{b}}$, Ivan Napoleão Bastos ${ }^{\mathrm{a} *}$

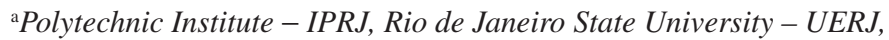 \\ CEP 28625-570, Nova Friburgo, RJ, Brazil \\ ${ }^{b}$ Laboratoire d'Electrochimie et de Physicochimie des Matériaux et des Interfaces-LEPMI, Grenoble \\ INP - Grenoble Institute of Technology, Université de Savoie, UMR5279 CNRS, Chambéry, \\ France, Université Joseph Fourier - UJF, BP 75, 38402 St Martin d'Hères, France
}

Received: November 27, 2012; Revised: January 17, 2013

\begin{abstract}
Superduplex stainless steel has been frequently employed in new sites of Brazilian Pre-Salt. In these environments, chloride concentration, temperature and carbon dioxide are normally present in higher levels than those at sea water at room temperature. In these conditions, it is expected that the passive films of stainless steel also show modifications. To better understand such modifications, samples of superduplex stainless steel UNS S32750 were submitted to electrochemical impedance measurements in brine media, at two temperatures and under presence/absence of carbon dioxide. The electrochemical impedance results were initially tested using the Kramers-Kronig transform and subsequently fitted by equivalent circuit employing constant phase elements - CPE. Moreover, to quantify the effect of each factor (temperature, chloride, carbon dioxide and microstructure) on the equivalent circuit, their parameters were tested applying statistical analysis. Significant effect of carbon dioxide and temperature was found on related parameters of passive film for heat-treated samples.
\end{abstract}

Keywords: superduplex stainless steel, electrochemical impedance, equivalent circuit, carbon dioxide, heat-treatments

\section{Introduction}

Commercial companies face challenging situations when exploiting oil and gas in offshore fields whose access is difficult and the environment may be extremely aggressive. Hydrocarbon sources existing on Brazilian Pre-Salt, for example, present temperature and salinity, besides harmful gas, in which the use of ordinary carbon steels become unfeasible since the corrosion effect is intensified by the local conditions. Another aggressive factor is the presence of carbon dioxide that promotes the $\mathrm{pH}$ reduction due to the $\mathrm{H}_{2} \mathrm{CO}_{3}$ formation ${ }^{1}$ and it well-known to be a major problem in corrosion behavior of iron based alloys ${ }^{2-6}$. An alternative is the use of corrosion resistant alloys like superduplex stainless steel that exhibit high corrosion resistance and good mechanical properties ${ }^{2}$. Such alloys have thin passive film, essentially constituted by $\mathrm{Cr}_{2} \mathrm{O}_{3}$, cohesive and self-regenerative, which is responsible for the excellent corrosion resistance ${ }^{7}$. The superduplex stainless steel shows, in addition to excellent pitting resistance number, small grain of austeno-ferritic microstructure and alloy elements as $\mathrm{Cr}, \mathrm{Mo}, \mathrm{N}$ and $\mathrm{Ni}$, which assure superior properties $^{8}$. Nevertheless, the heat-treatments used during the production of equipments may cause the precipitations of deleterious intermetallic components like sigma phase, making the steel more susceptible to localized corrosion².

*e-mail: inbastos@iprj.uerj.br
To better understand the passive film behavior of superduplex stainless steel at different conditions of environment and microstructure, measurements of electrochemical impedance spectroscopy (EIS) were performed. Such technique comprises applying a small amplitude potential excitation signal to the interface at different frequencies and registering the corresponding linear current response.The ratio between the Fourier or Laplace transforms of the applied perturbation and response signal defines the impedance ${ }^{9}$. Once the experimental diagrams of electrochemical impedance are obtained, it is possible to fit them with the help of equivalent electric circuits, EEC, comprising elements like resistors, capacitors and others. The overall electrical impedance of these EECs hence matches those of experimental electrochemical measurements. Moreover, each element from equivalent circuit must be related to physical aspects of the studied sample, if possible. In the present paper, the parameters of equivalent circuit were evaluated in order to investigate the effects of temperature, carbon dioxide, salinity and heattreatment on the passive film of UNS S32750 stainless steel.

\section{Material and Methods}

Sixteen experiments that compose a $2^{4}$ orthogonal experimental design, four factors at two levels, are shown in 
Table 1. Numbers 1 and 2 stand for the two heat-treatments performed at $800^{\circ} \mathrm{C}$ for 15 minutes or 2 hours respectively. Table 2 presents the nominal chemical composition of UNS S32750. Figure 1 shows the microstructures of heat-treated stainless steels during 15 minutes (a) and 2 hours (b). Sample of Figure 1a (15 min) presents incipient intergranular sigma precipitates that were clearly observed at the alpha/gamma interface, while sample $1 \mathrm{~b}$ ( 2 hours) reveals considerable amount of sigma phase.

The first heat-treatment simulates welding processes and the second mechanical hot-work process ${ }^{1}$. For the $\mathrm{CO}_{2}$ factor, number 1 represents the absence of gas whilst number 2 its presence. The $\mathrm{NaCl}$ factor comprises the electrolytic solution of sodium chloride used in concentrations of 70 and 140 ppt (parts per thousand, simulating the high concentration of chloride that can be found in regions of the Brazilian Pre-Salt layer). Finally, the working temperatures were 30 and $60{ }^{\circ} \mathrm{C}$ thermostated thanks to a double wall electrochemical cell.

\subsection{Kramers-Kronig transforms}

The increase of EIS technique use in diverse systems results in the appearance of a vast variety of spectra, making it difficult to evaluate, by simple inspection, if the results are valid or contains some experimental errors. The KramersKronig (KK) transformations are performed to validate EIS experimental according to four conditions ${ }^{10}$. The condition of causality demands that the system response is only sensible to the imposed perturbation; the linearity implies the use of sufficiently small amplitudes, about $10 \mathrm{mV}$, to assure tha tresponse is independent of perturbation amplitude but linear; the stability requires that the system return to its initial condition when the perturbationis ceased; and finally, the impedance must be a continuous function with finite values to any frequency, including frequencies close to zero or infinite.

If the four conditions above are obeyed, then the following Kramers-Kronig equations are valid ${ }^{10}$.

$$
\begin{aligned}
& Z_{r e}(\omega)=Z_{r e}(\infty)+\left(\frac{2}{\pi}\right) \int_{0}^{\infty} \frac{x Z_{i m}(x)-\omega Z_{\text {im }}(\omega)}{x^{2}-\omega^{2}} d x \\
& Z_{i m}(\omega)=\left(\frac{-2 \omega}{\pi}\right) \int_{0}^{\infty} \frac{Z_{r e}(x)-Z_{r e}(\omega)}{x^{2}-\omega^{2}} d x \\
& \theta(\omega)=\left(\frac{2 \omega}{\pi}\right) \int_{0}^{\infty} \frac{\ln |Z(x)|}{x^{2}-\omega^{2}} d x
\end{aligned}
$$

Where $\omega$ is the angular frequency $(\omega=2 \varpi f)$ and the others are defined as usual for EIS.

Equations 1, 2 and 3 allow recalculating the components of impedance values from the EIS experiments results and therefore evaluate their validity. In the present paper the

Table 1. Experimental conditions.

\begin{tabular}{lll}
\hline \multirow{2}{*}{ Factor } & \multicolumn{2}{c}{ Levels } \\
\cline { 2 - 3 } & \multicolumn{1}{c}{ low } & \multicolumn{1}{c}{ high } \\
\hline Microstructure & $1-\left(800{ }^{\circ} \mathrm{C}\right.$ for $\left.15 \mathrm{~min}\right)$ & $2-\left(800{ }^{\circ} \mathrm{C}\right.$ for 2 hour $)$ \\
$\mathrm{NaCl}$ & $70 \mathrm{ppt}$ & $140 \mathrm{ppt}$ \\
$\mathrm{Temperature}$ & $30{ }^{\circ} \mathrm{C}$ & $60{ }^{\circ} \mathrm{C}$ \\
$\mathrm{CO}_{2}$ & $1-($ without bubbling $)$ & $2-($ with bubbling $)$ \\
\hline
\end{tabular}

Table 2. Chemical composition of UNS S32759 stainless steel (\%mass) $)^{8}$.

\begin{tabular}{ccccccccccc}
\hline $\mathbf{C}$ & $\mathbf{C r}$ & $\mathbf{N i}$ & $\mathbf{M o}$ & $\mathbf{N}$ & $\mathbf{M n}$ & $\mathbf{S}$ & $\mathbf{P}$ & $\mathbf{S i}$ & $\mathbf{C u}$ \\
\hline 0.020 & 24.6 & 6.68 & 3.8 & 0.26 & 0.83 & 0.001 & 0.026 & 0.34 & 0.25 \\
\hline
\end{tabular}

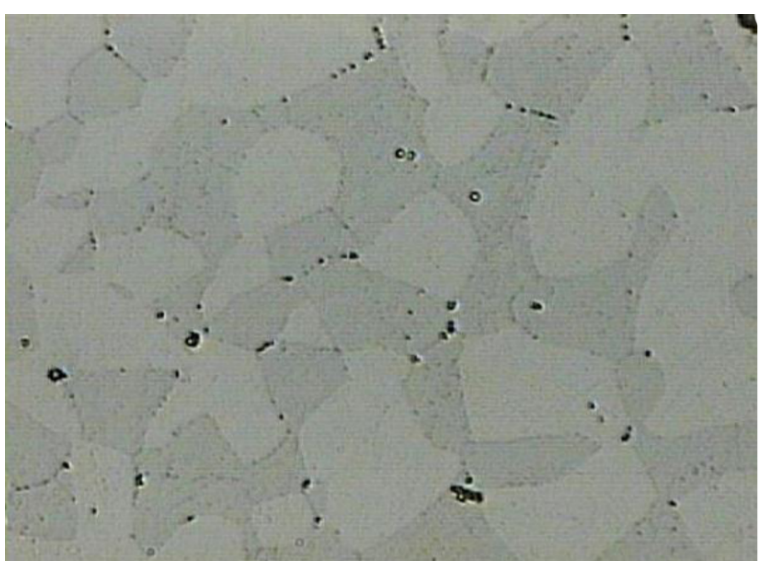

(a)

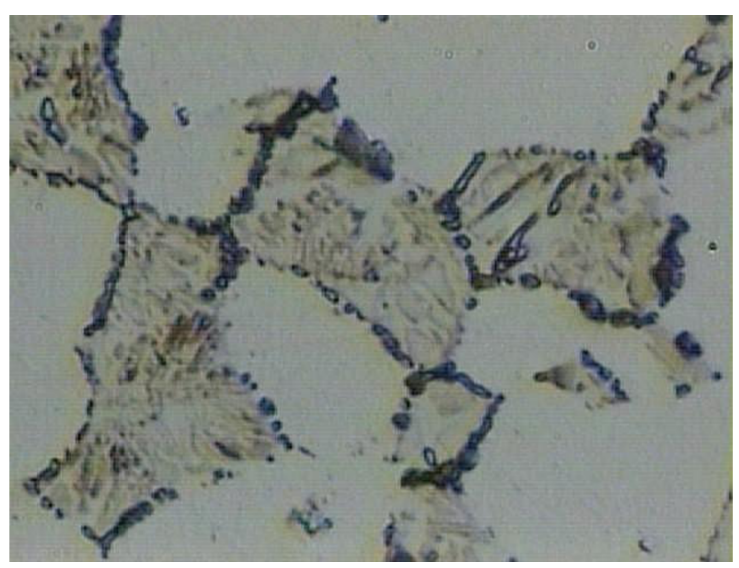

(b)

Figure 1. Microstructures of heat-treated UNS S32750 at $800{ }^{\circ} \mathrm{C}$. (a) 15 minutes, (b) 2 hours. 
EIS300 Electrochemical Impedance Spectroscopy software was used for $\mathrm{KK}$ analysis.

\subsection{Equivalent circuit for stainless steel}

After some fitting attempts of impedance diagrams using different equivalent circuit models, the one that better represented the experiments results is shown in Figure 2 and was already performed in literature to represent stainless steels interface ${ }^{11,12}$. This circuit was implemented with in ZView 3.2c software. A constant phase element (CPE) circuitry was utilized, and its individual impedance formula is represented in Equation 4

$$
Z_{C P E}=\frac{1}{(j \omega)^{\alpha} Q}
$$

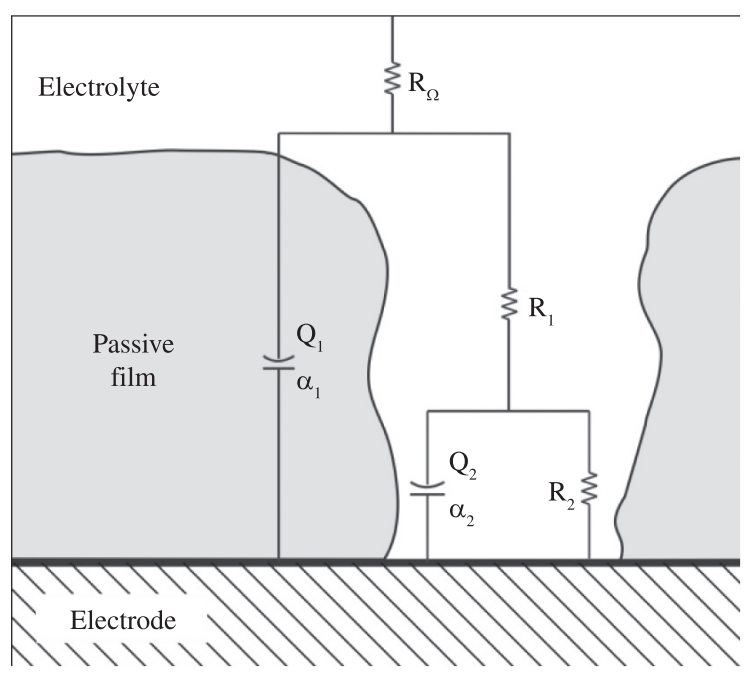

Figure 2. Equivalent circuit.
Where $\alpha$ and $\mathrm{Q}$ are CPE parameters and $\mathrm{j}$ is the imaginary coefficient. The physical meaningof this element changes according to $\alpha$ values. If $\alpha=1 \mathrm{CPE}$ behaves like a capacitor and the parameter $\mathrm{Q}$ is then equivalent to a capacitor $\mathrm{C}$. When $\alpha<1$ the system shows a behavior that has been frequently attributed to metal surface heterogeneity ${ }^{13}$ even if several other causes for CPE behavior to appear have been proposed $^{14}$. When $\alpha=0.5 \mathrm{CPE}$ is equivalent to Warburg element that is performed to represent diffusion processes, and if $\alpha=0$ CPE behaves like a resistor ${ }^{11,12}$.

The meaning of elements used in equivalent circuit is related hereafter according to literature ${ }^{11,12} . \mathrm{R}_{\Omega}$ represents the electrolyte resistance, $\mathrm{Q}_{1}$ represents the capacitive behavior of passive film and $\mathrm{R}_{1}$ the resistance of ionic flux, $Q_{2}$ represents the capacitive behavior of the metal interface and $R_{2}$ the charge transfer resistance.

\subsection{Statistical analysis}

In order to optimize the evaluation process of experimental results, the Statgraphics Centurion XVI software was used to perform the full factorial analysis of the $2^{4}$ orthogonal experimental design. The microstructure and $\mathrm{CO}_{2}$ factors were classified as qualitative and the $\mathrm{NaCl}$ and temperature factors were classified as quantitative, as shown in Table 1 . The statistical analysis reveals the individual effects, as well as its synergisms, and the significances. The experimental runs were entitled as 1 to 16 according to their conditions, as presented in Table 3.

\section{Results and Discussion}

The results of KK analysis suggested that the EIS experiments obeyed the four necessary conditions to validate the electrochemical impedance measurements since the associated errors were acceptable. The values of goodness of fit provided by software were between $17 \times 10^{-6}$ for experiment 4 and $455 \times 10^{-6}$ for experiment 14 . Figure 3

Table 3. Experimental running.

\begin{tabular}{ccccc}
\hline Experiment & $\begin{array}{c}\text { Microstructure } \\
\mathbf{1 - 1 5} \text { min } \\
\mathbf{2 - 2} \text { hour }\end{array}$ & $\begin{array}{c}\text { NaCl } \\
(\mathbf{p p t})\end{array}$ & $\begin{array}{c}\text { Temperature } \\
\left({ }^{\circ} \mathbf{C}\right)\end{array}$ & $\begin{array}{c}\text { CO } \mathbf{2}_{\mathbf{2}} \\
\text { 1-without bubbling } \\
\text { 2- with bubbling }\end{array}$ \\
\hline 1 & 1 & 140 & 30 & 1 \\
2 & 2 & 140 & 60 & 2 \\
3 & 1 & 140 & 60 & 1 \\
4 & 2 & 140 & 60 & 1 \\
5 & 2 & 70 & 60 & 2 \\
6 & 1 & 140 & 30 & 1 \\
7 & 1 & 30 & 1 \\
8 & 1 & 70 & 60 & 2 \\
9 & 2 & 30 & 2 \\
10 & 1 & 140 & 60 & 2 \\
11 & 2 & 70 & 30 & 1 \\
13 & 2 & 70 & 30 & 2 \\
14 & 2 & 70 & 30 & 2 \\
16 & 1 & 140 & 30 & 1 \\
\hline
\end{tabular}


graphically depicts the KK results by Bode and Nyquist diagrams taking experiment 9 as an example since the goodness of its fit falls by the middle of the determined range $\left(288 \times 10^{-6}\right)$. The residual errors from real and imaginary impedances are dependent on frequency ${ }^{15}$ but were small and fluctuated around zero which qualitatively corroborates the goodness of the results.

Besides the similarity between the experimental data and KK fitting observed on Bode and Nyquist diagrams, was also noted, in all experiments, that the residuals errors from real and imaginary impedances were higher in low frequencies between $10^{-3}$ and $10^{-2} \mathrm{~Hz}$. This behavior is due to the passive film evolution and could be normally expected.

The equivalent circuit from Figure 2 was able to fit the EIS experimental results with good precision. The $\chi^{2}$ (chi-square) deviation values presented order-of-magnitude of $10^{-4}$ as shown in Table 3 and are in accordance with literature ${ }^{11}$. In Figure 4 are presented the Bode and Nyquist diagrams of equivalent circuit fitting for experiment 1 . For the sake of conciseness, the other diagrams are not showed.

Table 4 summarizes the fitting values of parameters used in equivalent circuit and the respective errors for the 16 experiments. The $\mathrm{R}_{\Omega}, \mathrm{Q}_{1}$ and $\alpha_{1}$ parameters presented the smallest errors and maintained such values low in all performed fitting. The other parameters showed, in average, error values slightly higher, notwithstanding in some situations such values had been considerable higher as the $\mathrm{Q}_{2}$ parameter of experiment 1 and 2, and $\mathrm{R}_{1}$ for experiment 9 .

To a significance level of $5 \%$ the factorial analysis exhibited statistically significant variation to $\mathrm{Q}_{1}, \alpha_{1}$ and
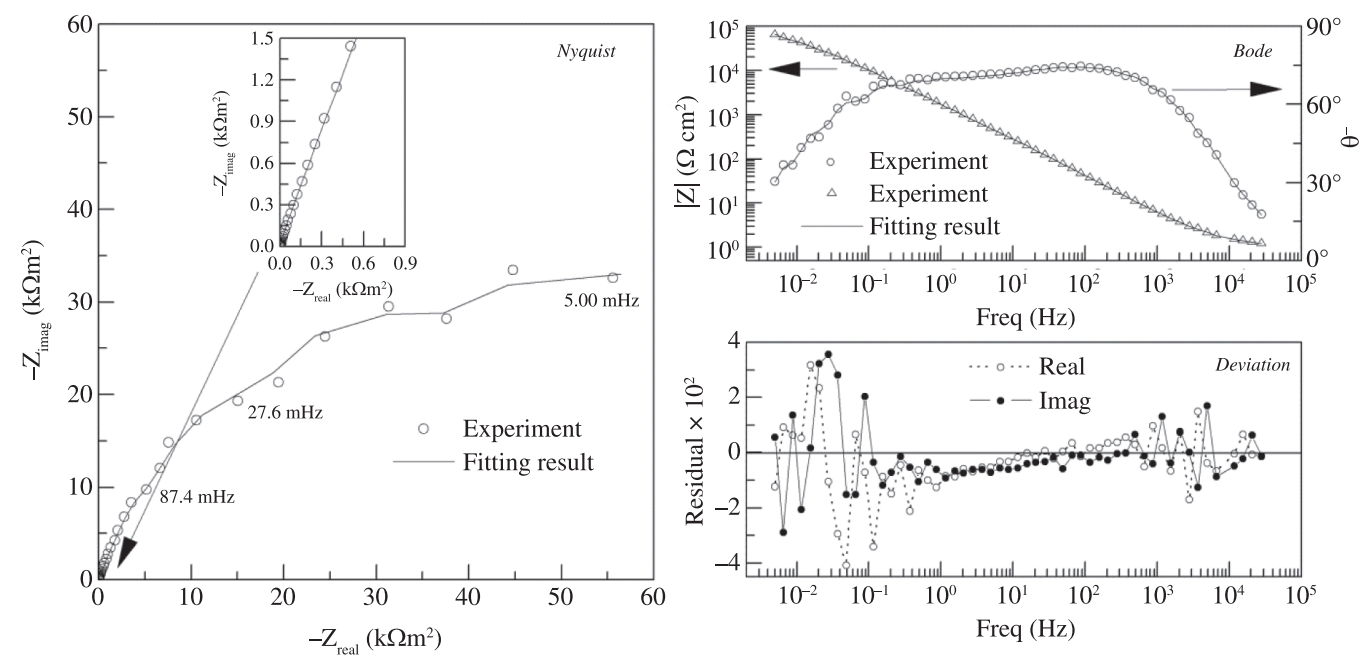

Figure 3. Kramers-Kronig analysis for experiment 9.

Table 4. Fitting of equivalent circuit parameters.

\begin{tabular}{|c|c|c|c|c|c|c|c|c|c|c|c|c|c|c|c|c|}
\hline \multirow{2}{*}{ Parameter } & \multicolumn{16}{|c|}{ Experiment } \\
\hline & 1 & 2 & 3 & 4 & 5 & 6 & 2 & 8 & 9 & 10 & 11 & 12 & 13 & 14 & 15 & 16 \\
\hline $\mathrm{R}_{\Omega}\left(\Omega \mathrm{cm}^{2}\right)$ & 4.1 & 0.7 & 1.0 & 0.8 & 1.2 & 1.2 & 1.8 & 3.7 & 1.3 & 2.8 & 2.0 & 2.2 & 1.4 & 3.1 & 1.3 & 0.9 \\
\hline Error $(\%)$ & 0.6 & 0.9 & 3.2 & 1.0 & 2.0 & 1.0 & 0.7 & 0.3 & 2.2 & 0.6 & 1.0 & 0.8 & 1.0 & 1.0 & 1.0 & 0.9 \\
\hline$Q_{1}\left(\mu \frac{s^{\alpha_{1}}}{\Omega^{2} c m^{2}}\right)$ & 83.2 & 178 & 113 & 49.9 & 49.7 & 131 & 80.3 & 60.5 & 99.3 & 124 & 80.4 & 73.6 & 51.1 & 103 & 184 & 49.9 \\
\hline Error $(\%)$ & 0.7 & 0.6 & 6.9 & 3.5 & 2.6 & 0.8 & 1.5 & 0.4 & 5.2 & 1.5 & 2.0 & 5.2 & 1.4 & 2.2 & 3.0 & 1.1 \\
\hline$\alpha_{1} \times 10^{3}$ & 880 & 819 & 875 & 900 & 900 & 864 & 837 & 904 & 850 & 831 & 898 & 870 & 884 & 863 & 805 & 894 \\
\hline Error (\%) & 0.2 & 0.1 & 1.0 & 0.4 & 0.4 & 0.2 & 0.2 & 0.1 & 0.8 & 0.3 & 0.3 & 0.7 & 0.2 & 0.4 & 0.4 & 0.2 \\
\hline $\mathrm{R}_{1}\left(\mathrm{k} \Omega \mathrm{cm}^{2}\right)$ & 134 & 26.7 & 0.92 & 0.13 & 2.37 & 24.5 & 0.69 & 62.6 & 2.05 & 5.7 & 4.63 & 0.07 & 4.56 & 11.1 & 0.03 & 15.1 \\
\hline Error (\%) & 16 & 5.8 & 47 & 6.2 & 16 & 8.3 & 13 & 9.7 & 50 & 18 & 23 & 3.4 & 9.2 & 36 & 3.8 & 26 \\
\hline$Q_{2}\left(\mu \frac{s^{\alpha_{2}}}{\Omega^{2} c m^{2}}\right)$ & 52.3 & 552 & 55.1 & 85.5 & 46.9 & 201 & 6.89 & 44.1 & 42.9 & 41.7 & 47.5 & 143 & 38.4 & 23.3 & 99.1 & 12.2 \\
\hline Error (\%) & 74 & 64 & 13 & 2.2 & 2.6 & 28 & 18 & 38 & 10 & 4.1 & 3.3 & 2.8 & 1.8 & 9.5 & 5.6 & 4.7 \\
\hline$\alpha_{2} \times 10^{3}$ & 861 & 871 & 712 & 755 & 657 & 613 & 1010 & 615 & 666 & 669 & 585 & 917 & 685 & 732 & 972 & 648 \\
\hline Error (\%) & 19 & 19 & 3.0 & 0.4 & 1.9 & 14 & 3.2 & 11 & 4.3 & 2.5 & 3.0 & 0.5 & 1.3 & 5.1 & 1.0 & 3.2 \\
\hline $\mathrm{R}_{2}\left(\mathrm{k} \Omega \mathrm{cm}^{2}\right)$ & 97.1 & 8.19 & 99.7 & 98.4 & 180 & 61.0 & 282 & 48.5 & 88.6 & 188 & 230 & 191 & 195 & 191 & 91.9 & 298 \\
\hline Error (\%) & 28 & 25 & 6.2 & 1.7 & 5.9 & 27 & 2.0 & 16 & 6.3 & 5.2 & 9.0 & 3.5 & 3.1 & 6.4 & 3.1 & 4.0 \\
\hline$\chi^{2} \times 10^{4}$ & 14 & 5.9 & 68 & 7.8 & 20 & 12 & 8.1 & 2.5 & 56 & 7.9 & 15 & 15 & 8.4 & 23 & 13 & 8.0 \\
\hline
\end{tabular}


$\alpha_{2}$ variables. In Figures 5, 6 and 7 are shown the results of statistical analysis to these parameters by the standardized Pareto chart. The significance of factors and the synergisms are presented in decreasing order. The factors whose significance values reach the vertical standardized line are classified as significant. Moreover, the label indicates how each factor influences a given variable. In this analysis, the variable effect that increase the factor significance value is described as positive, and the opposite behavior is identified as negative. In Figure 5, for example, if the $\mathrm{CO}_{2}$ level increases, the variable $\mathrm{Q}_{1}$ raises its value. The microstructure, $\mathrm{NaCl}$, temperature and $\mathrm{CO}_{2}$ factors were respectively represented as $\mathrm{A}, \mathrm{B}, \mathrm{C}$ and $\mathrm{D}$.

Figures 5 and 6 suggest that the carbon dioxide influences the passive film. Indeed, it clearly appears that it alters only the significant values of $Q_{1}$ and $\alpha_{1}$ parameters which are related to the passive film behavior. Thus, $\mathrm{Q}_{1}$ parameter (Figure 5) under $\mathrm{CO}_{2}$ effect was about 2.5 times higher than the threshold value to be considered statistically significant.
The temperature/CO (labeled $\mathrm{CD}$ ) and microstructure/ temperature (AC) synergisms were also classified as significant in Figure 5, even if their significant values to these parameters were not so intense than $\mathrm{CO}_{2}$. In Figure 6 the temperature/ $\mathrm{CO}_{2}-\mathrm{CD}$ synergism presented a significant value comparable to $\mathrm{CO}_{2}$ for $\alpha_{1}$, but with a negative effect. This result is in good agreement with some recent findings in the literature showing that $\mathrm{Q}$ and $\alpha$ values are inversely and intrinsically coupled, that is, an increase (conversely decrease) in $\mathrm{Q}$ is mutually compensated by a decrease (increase) in alpha ${ }^{14}$ as it appears from Figures 5 and 6. Finally, Figure 7 indicates that the temperature $/ \mathrm{CO}_{2}$ and microstructure/temperature synergisms are significant to $\alpha_{2}$.

Table 4 depicts the statistical analysis results. The $\mathrm{Q}_{1}$ parameter values were substantially higher in $\mathrm{CO}_{2}$ presence that, according to the literature ${ }^{12}$, indicates an increase of surface film defects. Indeed, capacitance is proportional to the film permittivity that increases with the presence of defects. Moreover, the increment of temperature
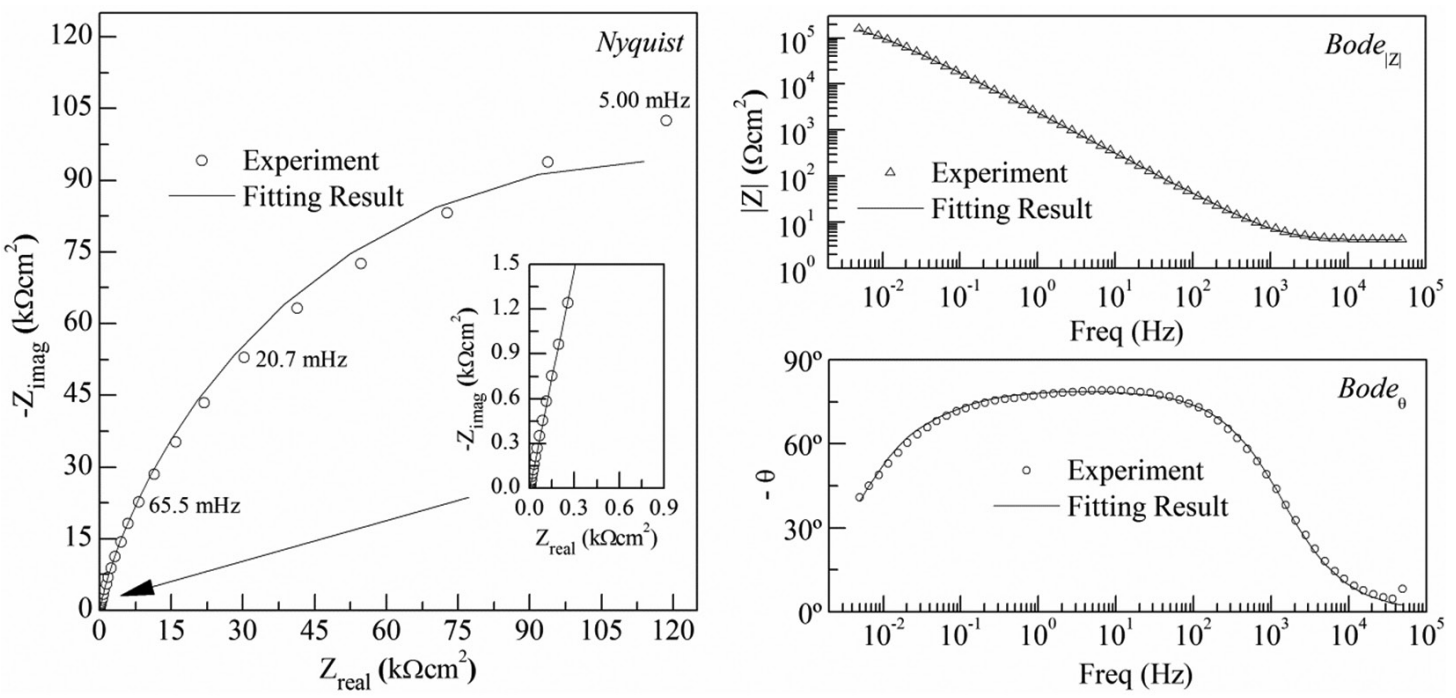

Figure 4. Equivalent circuit fitting of experiment 1.

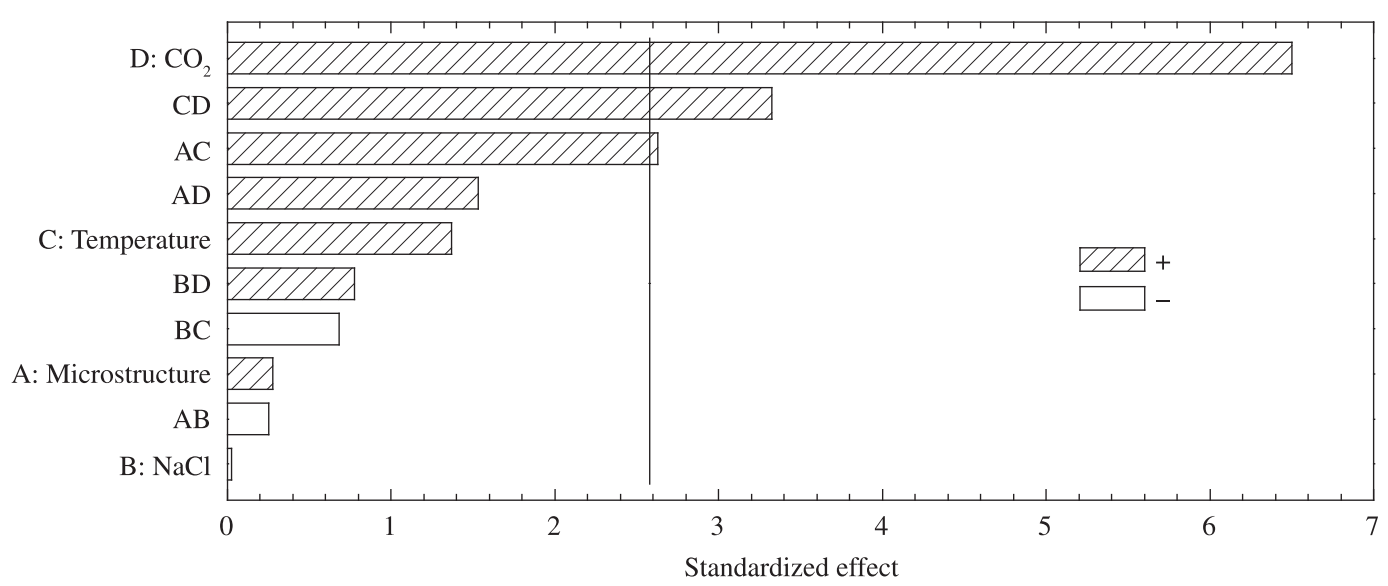

Figure 5. Significance analysis of parameter $\mathrm{Q}_{1}$. 


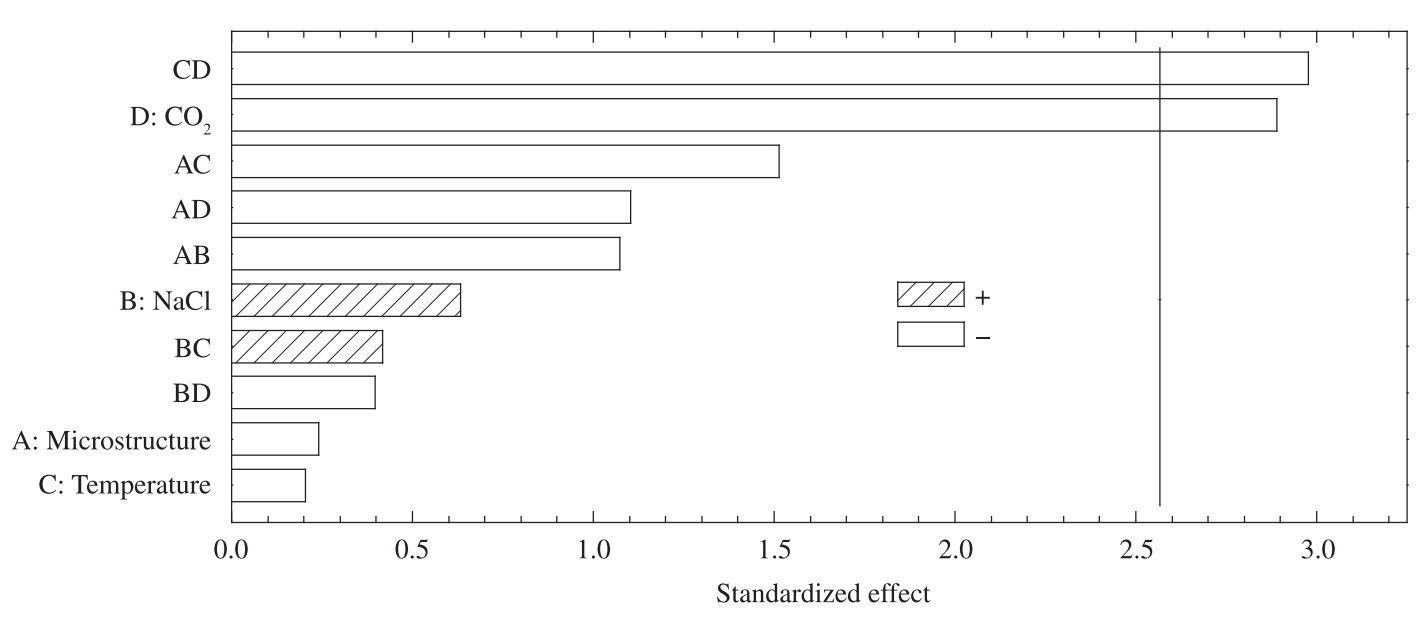

Figure 6. Significance analysis of parameter $\alpha_{1}$.

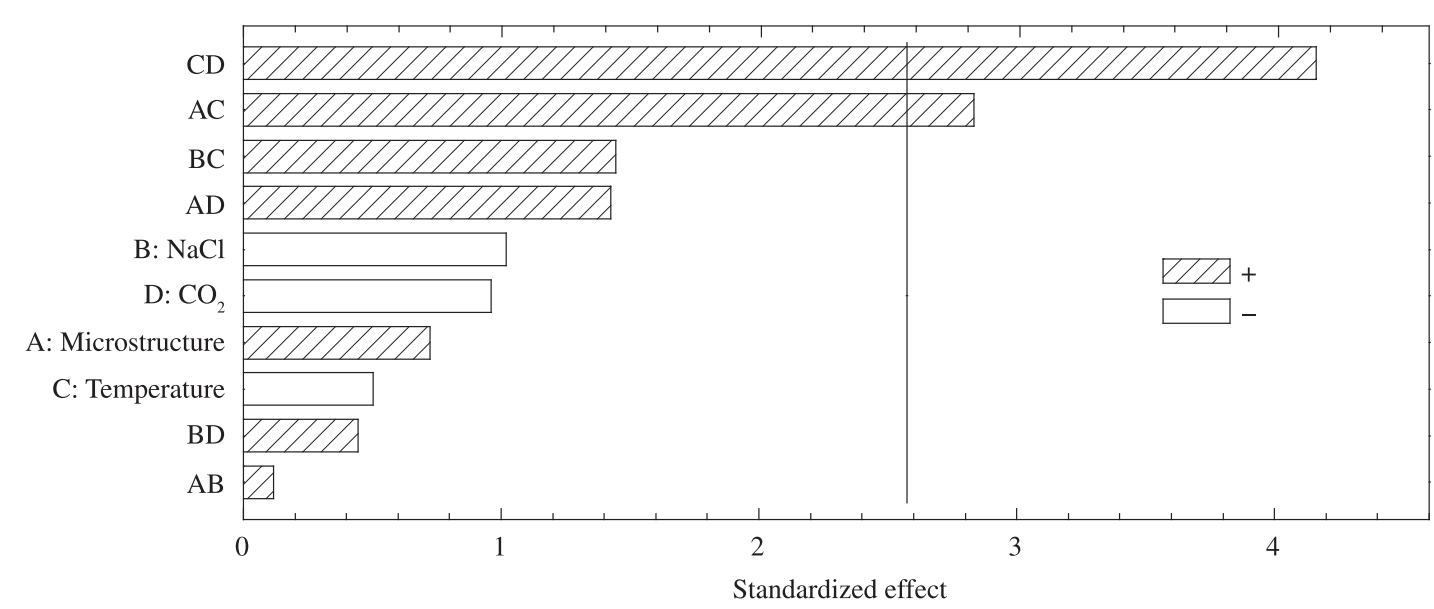

Figure 7. Significance analysis of parameter $\alpha_{2}$

intensified the $\mathrm{CO}_{2}$ effect on $\mathrm{Q}_{1}$. This information may be better observed in Figure 8 in which are represented the $\mathrm{Q}_{1,2} / \mathrm{Q}_{1,1}$ ratio values as a function of temperature, where $\mathrm{Q}_{1,2}$ represents the $\mathrm{Q}_{1}$ parameter measured in $\mathrm{CO}_{2}$ presence, and $\mathrm{Q}_{1,1}$ represents the same parameter measured in the same conditions of microstructure, $\mathrm{NaCl}$ and temperature, but in $\mathrm{CO}_{2}$ absence.

As all $Q_{1,2} / Q_{1,1}$ ratio values are higher than unit, then for all cases $\mathrm{Q}_{1,2}>\mathrm{Q}_{1,1}$ meaning that the presence of carbon dioxide was deleterious to passive film. Moreover, all curves present positive inclinations, so that the increment of temperature from 30 to $60{ }^{\circ} \mathrm{C}$ resulted in the increase of $\mathrm{Q}_{1,2} / \mathrm{Q}_{1,1}$ ratio, intensifying the deleterious effect of $\mathrm{CO}_{2}$. Besides, the higher linear slope suggests that the raise of temperature was more aggressive to microstructure 2 , which contains higher microstructural heterogeneity and presents higher sensibility. It is noteworthy that the statistical orthogonal design considers

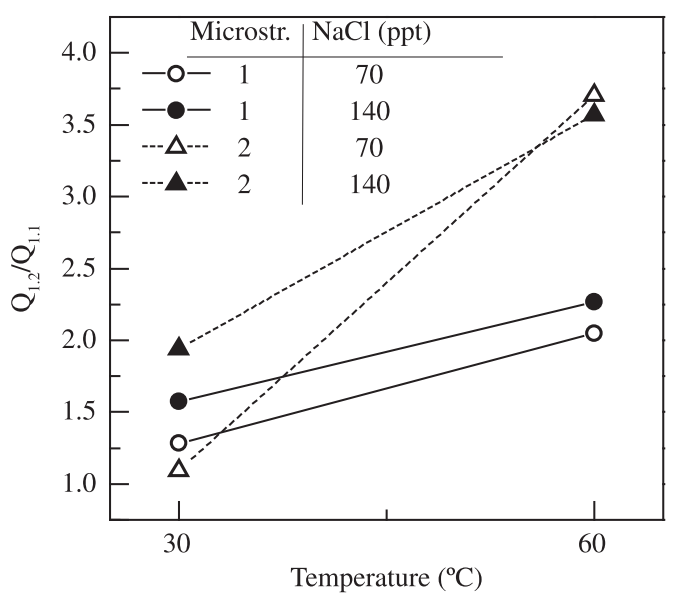

Figure 8. Effect of $\mathrm{CO}_{2}$ and temperature on $\mathrm{Q}_{1}$ parameter. $\mathrm{Q}_{1,1}$ without and $\mathrm{Q}_{1,2}$ with $\mathrm{CO}_{2}$. 


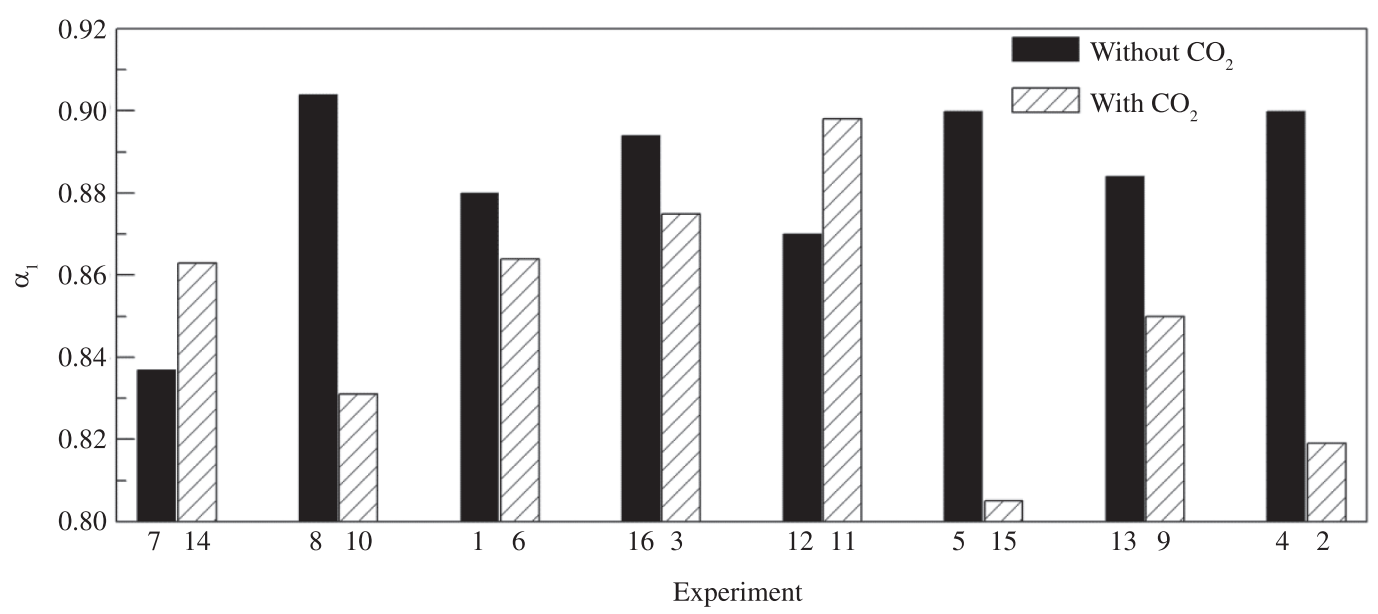

Figure 9. Effect of $\mathrm{CO}_{2}$ on $\alpha_{1}$ parameter.

linear the factor effect, as depicted in Figure 8. Thus, each data point represents an average of eight experiments with a given factor at a single level.

Another parameter that presented interesting behavior relative to $\mathrm{CO}_{2}$ presence/absence was $\alpha_{1}$, whose values were lower in most of experiments containing the gas. Such behavior is represented in Figure 9 and it was a priori expected. Indeed, since the presence of $\mathrm{CO}_{2}$ induces a proliferation of defects upon the film, hence increasing the heterogeneity distribution, this is effectively expected to appear in the form of smaller values of alpha, which means, larger deviations from the "ideal" capacitance predicted for "perfect" films.

While $\alpha_{1}$ values remained within 0.8 and $0.9, \alpha_{2}$ presented more variable values, ranging from 0.6 to 1 . Thus the latter average was lower than $\alpha_{1}$, as shown in Table 4 . Such result suggests that at the global metallic-electrolyte interface, with passive film defects, can be influenced by diverse phenomena. Therefore, the global impedance is hardly represented by a simple equivalent circuit when a parallel diffusion across the film defect occurs, and $\alpha_{2}$ values would be close to 0.5 . Moreover, $\mathrm{Q}_{2}, \mathrm{R}_{\Omega}, \mathrm{R}_{1}$ and $\mathrm{R}_{2}$ factors did notexhibited statistically significant variation to a significance level of $5 \%$.

An additional effect of bubbling $\mathrm{CO}_{2}$ is the reduction of $\mathrm{pH}$, approximately from 7 to $4^{1}$. This reduction changes the valence of certain metals, as nickel, and chiefly the molybdenum. For high chloride content and moderate

\section{References}

1. Mesquita TJ, Nogueira RP and Bastos IN. Factorial design applied to corrosion of superduplex stainless steel. Latin American Applied Research. 2011; 41:311-315.

2. Bastos IN, Tavares SSM, Dalard F and Nogueira RP. Effect of microstructure on corrosion behavior of superduplex stainless steel at critical environment condition. Scripta Materialia. 2007; 57:913-916. http://dx.doi.org/10.1016/j. scriptamat.2007.07.037

3. Amri J, Gulbrandsen E and Nogueira RP. Pit growth and stifling on carbon steel in $\mathrm{CO}_{2}$-containing media in the presence of temperature, Wang et al ${ }^{16}$ have remarked the strong stability of $\mathrm{Mo}$ (III) for large $\mathrm{pH}$ range at $80{ }^{\circ} \mathrm{C}$. This solubility can worse the film properties from 30 to $60{ }^{\circ} \mathrm{C}$ as observed in Figure 8.

It is worth noticing that in the present work we were interested in identifying which variables can, isolated or couple to others, be considered as harmful parameters for the corrosion performance of heat-treated stainless steel in these media, regardless the theoretical reaction models behind it. Therefore, the comparison with theoretical reaction models is beyond the aims of the present paper.

\section{Conclusion}

The electrochemical impedance spectroscopy diagram analysis of heat-treated superduplex stainless steel UNS S32750 indicates that carbon dioxide presence is harmful to the studied passive film. The gas presence increases the defects on steel passive layer and makes it more heterogeneous. Moreover, this deleterious effect is intensified at higher temperature thus the combination of these two factors, $\mathrm{CO}_{2}$ and temperature, further reduces the protective characteristics of films tested by electrochemical impedance and fitted by constant phase element circuit.

\section{Acknowledgements}

The authors acknowledge the financial support of $\mathrm{CNPq}$, CAPES and FAPERJ Brazilian agencies.

HAc. Electrochimica Acta. 2009; 54:7338-7344. http://dx.doi. org/10.1016/j.electacta.2009.07.061

4. Nesic S, Postlethwaite J and Olsen S. An electrochemical model for prediction of corrosion of mild steel in aqueous carbon dioxide solutions. Corrosion. 1996; 52:280-294. http://dx.doi. org/10.5006/1.3293640

5. Nyborg R. Overview of $\mathrm{CO}_{2}$ corrosion models for wells and pipelines. In: Proceedings of the Corrosion; 2002; Denver. Houston: NACE International; 2002. paper n. 02233.

6. Amri J, Gulbrandsen E and Nogueira RP. The effect of acetic acid on the pit propagation in $\mathrm{CO}_{2}$ corrosion of carbon steel. 
Electrochemistry Communications. 2008; 10:200-203. http:// dx.doi.org/10.1016/j.elecom.2007.11.028

7. Magnabosco R. Influence of microstructure on electrochemical behavior of stainless steel UNS S31803 (SAF 2205). [Thesis]. São Paulo: University of São Paulo; 2001. (in Portuguese).

8. Tavares SSM, Pardal JM, Lima LD, Bastos IN, Nascimento AM and Souza JA. Characterization of microstructure, chemical composition, corrosion resistance and toughness of a multipass weld joint of superduplex stainless steel UNS S32750. Materials Characterization. 2006; 58:610-616. http:// dx.doi.org/10.1016/j.matchar.2006.07.006

9. Orazem ME and Tribollet B. Experimental Methods. In: Electrochemical impedance spectroscopy. Nova Jersey:Wiley; 2008. p. 427-445. http://dx.doi.org/10.1002/9780470381588.ch22

10. Orazem ME and Tribollet B. The Kramers-Kronig Relations. In: Electrochemical impedance spectroscopy. Nova Jersey: Wiley; 2008. p. 109-128. http://dx.doi. org/10.1002/9780470381588.ch22

11. Luo H, Dong CF, Li XG and Xiao K. The electrochemical behaviour of 2205 duplex stainless steel in alkaline solutions with different $\mathrm{pH}$ in the presence of chloride. Electrochimica Acta. 2012; 64:211-220. http://dx.doi.org/10.1016/j. electacta.2012.01.025
12. Hirschorn B, Orazem ME, Tribollet B, Vivier V, Frateur I and Musiani M. Determination of effective capacitance and film thickness from constant-phase-element parameters. Electrochimica Acta. 2010; 55:6218-6227. http://dx.doi. org/10.1016/j.electacta.2009.10.065

13. Kocijan A, Merl DK and Jenko M. The corrosion behaviour of austenitic and duplex stainless steels in artificial saliva with the addition of fluoride. Corrosion Science. 2011; 53:776-783. http://dx.doi.org/10.1016/j.corsci.2010.11.010

14. Cordoba-Torres P, Mesquita TJ, Devos O, Tribollet B, Roche V. and Nogueira RP. On the intrinsic coupling between constantphase element parameters $\alpha$ and Q in electrochemical impedance spectroscopy. Electrochimica Acta. 2012; 72:172-178. http:// dx.doi.org/10.1016/j.electacta.2012.04.020

15. Boukamp BA. Practical application of the Kramers-Kronig transformation on impedance measurements in solid state electrochemistry. Solid State Ionics. 1993; 63:131-141. http:// dx.doi.org/10.1016/0167-2738(93)90261-Z

16. Wang P, Wilson LL, Wesolowski DJ, Rosenqvist J and Anderko A. Solution chemistry of Mo(III) and Mo(IV): Thermodynamic foundation for modeling localized corrosion. Corrosion Science. 2010; 52:1625-1634. http://dx.doi.org/10.1016/j. corsci.2010.01.032 


\section{ERRATUM}

Due to an error on desktop publishing, the article: Effect of Carbon Dioxide and Temperature on Passive Film Parameters of Superduplex Stainless Steel (http://dx.doi.org/10.1590/S151614392013005000088), ahead of print on June 11st, was published with a wrong figure 3.

Please find below the correct figure 3:
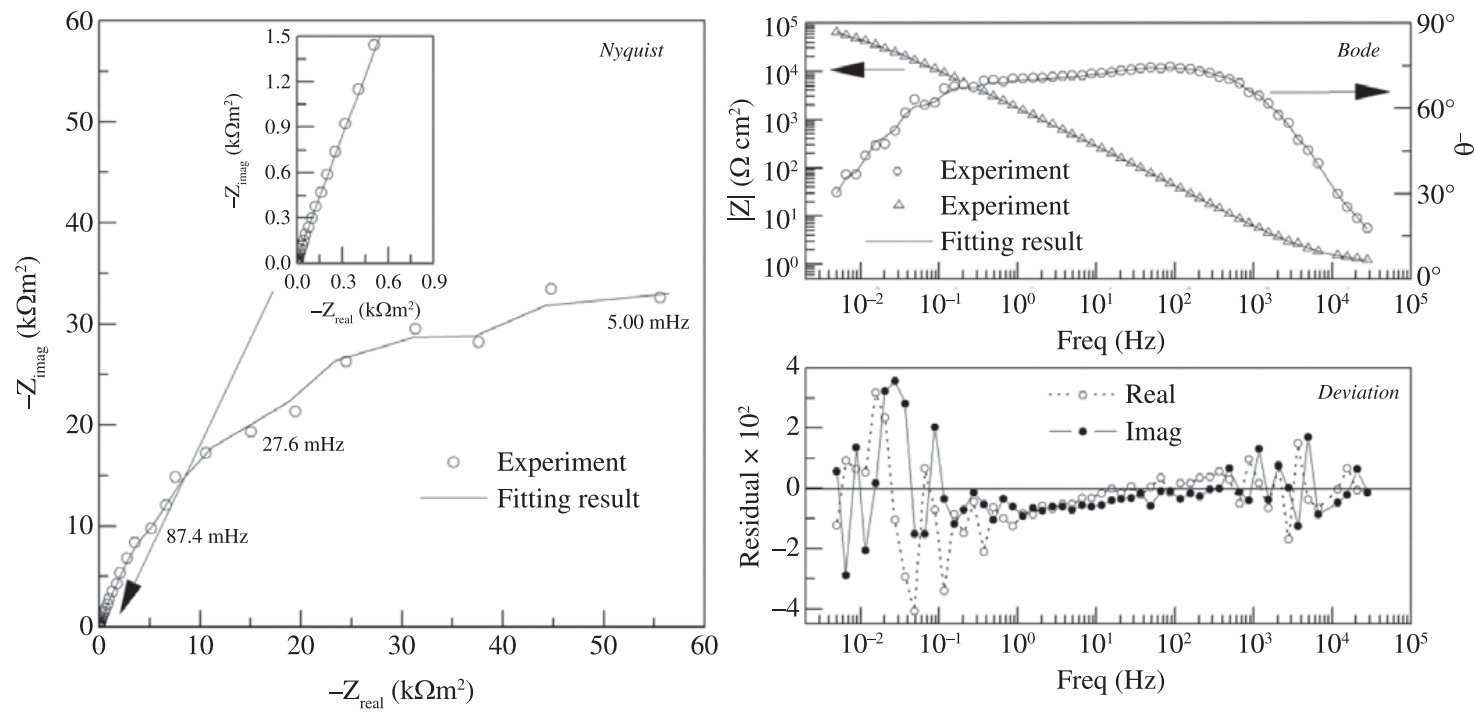